\title{
Morfometria e acúmulo de biomassa em palma forrageira sob doses de nitrogênio
}

\author{
Morphometric and biomass accumulation in small forage cactus grow under nitrogen \\ fertilization
}
CUNHA, Daniel de Noronha Figueiredo Vieira da ${ }^{1}$; GOMES, Edmarões dos Santos ${ }^{2}$; MARTUSCELLO, Janaina Azevedo ${ }^{1}$; AMORIM, Philipe Lima de ${ }^{3}$; SILVA, Randerson Cavalcante ${ }^{4}$; FERREIRA, Paulo Sérgio ${ }^{2}$

\author{
${ }^{1}$ Universidade Federal de São João Del-Rei, Campus Tancredo Neves, Departamento de Zootecnia, São \\ João Del-Rei, Minas Gerais, Brasil. \\ ${ }^{2}$ Universidade Federal de Alagoas, Departamento de Zootecnia, Arapiraca, Alagoas, Brasil. \\ ${ }^{3}$ Universidade Federal de Viçosa, Centro de Ciências Agrárias, Departamento de Zootecnia, Viçosa, \\ Minas Gerais, Brasil. \\ ${ }^{4}$ Universidade Estadual Paulista, Departamento de Zootecnia, Jaboticabal, São Paulo, Brasil. \\ *Endereço para correspondência: philipe.lima.zoot@gmail.com
}

\section{RESUMO}

Objetivou-se avaliar parâmetros morfológicos e de produção em Palma forrageira cv. Miúda, sob doses de adubo nitrogenado. Além disso, apontar características morfológicas que possam ser utilizadas como variáveis preditoras da massa fresca dos cladódios. O experimento foi conduzido num delineamento inteiramente casualizado, com quatro tratamentos (ausência de adubação nitrogenada, 100; 200 e 300kg/ha de nitrogênio) e quatro repetições. Não houve diferenças significativas $(\mathrm{P}>0,10)$ para as características morfogênicas e comprimento dos cladódios. A adubação nitrogenada exerceu efeito linear negativo para as características largura, espessura, volume e peso médio de cladódios e efeito linear positivo para número de cladódios. Houve correlação linear positiva entre a massa fresca e as características morfológicas dos cladódios. O uso da adubação nitrogenada não interfere nas características morfogênicas e na produção de biomassa da palma forrageira. $\mathrm{O}$ volume dos cladódios pode ser usado como variável preditora para a massa fresca dos cladódios.

\section{SUMMARY}

The objective was to evaluate morphological characteristics and forage production in cactus pear cv. Miúda subjected to nitrogen levels and pointing morphological characteristics that can be used as predictors of fresh weight of cladodes. The experiment was conducted in a completely randomized design with four treatments (no fertilization, 100; 200 and $300 \mathrm{~kg} / \mathrm{ha}$ of nitrogen) and four replications. No significant differences $(\mathrm{P}>0.10)$ for the morphogenesis and length of cladodes. Nitrogen fertilization exerted a linear effect for features width, thickness, volume and weight of cladodes and positive linear effect for number of cladodes. There was a positive linear correlation between fresh weight and morphological characteristics of cladodes. The use of nitrogen does not interfere with morphogenesis and biomass production of cactus pear. The volume of cladodes can be used as a predictive variable for the fresh weight of cladodes.

Keywords: correlations, fresh mass yield, nitrogen fertilization, semi-arid.

Palavras-chave: adubação nitrogenada, correlação, produção de massa fresca, semiárido. 


\section{INTRODUÇÃOO}

A palma forrageira consiste em um recurso alimentar importante (CAVALCANTI et al., 2008) para a região do semiárido nordestino. Características como, significantes produções de massa seca por unidade de área (SANTOS et al., 1997); altos teores de carboidratos não fibrosos (WANDERLEY et al., 2002); e nutrientes digestíveis totais (MELO et al., 2003), fizeram da mesma uma das forrageiras mais utilizadas na alimentação de bovinos leiteiros, principalmente, nas épocas secas (MAGALHÃES et al., 2004).

Devido aos processos pedogênicos dos solos do semiárido nordestino, os mesmos apresentam de maneira geral, baixos teores de matéria orgânica e, consequentemente, baixa disponibilidade de nitrogênio para as plantas. $\mathrm{O}$ nitrogênio participa da composição de diversas moléculas orgânicas no interior das plantas e é o principal controlador dos processos fotossintéticos.

Nesse contexto, a inserção de fontes externas de nitrogênio é imprescindível para a elevação da produção de biomassa da palma-forrageira, de modo a possibilitar reflexos positivos na rentabilidade do sistema produtivo. No entanto, ainda são escassos os resultados de ensaios que demonstram a resposta agronômica da palma-forrageira (cv. Miúda) sob fertilização nitrogenada. Essa falta, de certa forma, induz pecuaristas a utilizarem recomendações empíricas, o que gera, na maioria dos casos, respostas insatisfatórias, a causar descrédito acerca da adoção da tecnologia.

A morfogênese tem sido uma ferramenta utilizada em estudos sobre ecofisiologia de plantas forrageiras, sobretudo, em Poaceas. Com a morfogênese, é possível visualizar o fluxo de tecidos da planta através da conversão dos valores obtidos em taxas de alongamento, aparecimento e senescência. A morfogênese pode apresentar diferentes padrões de resposta, em face do manejo imposto à planta $\mathrm{e}$, ser utilizada também como uma ferramenta balizadora de ações de manejo em plantas forrageiras.

Existem poucos relatos dos efeitos diretos e indiretos das características morfológicas da palma forrageira sobre a produção. Assim, é necessário conhecer tais efeitos e as correlações entre a produtividade e traços morfológicos para identificação de características que influenciam a produção (SILVA et al., 2010).

Portanto, objetivou-se avaliar parâmetros morfológicos e de produção em Palma forrageira cv. Miúda, sob doses de adubo nitrogenado, e apontar características morfológicas que possam ser utilizadas como variáveis preditoras da massa fresca dos cladódios.

\section{MATERIAL E MÉTODOS}

O experimento foi conduzido na Universidade Federal de Alagoas Campus Arapiraca, no período de 19/06/09 a 25/02/11. Os totais de precipitação pluviométrica e médias mensais de temperatura máxima, mínima e média dos meses de junho de 2009 a fevereiro de 2011 podem ser observados na Figura 1.

Os tratamentos consistiram em três doses de adubação nitrogenada (100; 200 e $300 \mathrm{~kg} / \mathrm{ha}$ de nitrogênio) e um tratamento controle (sem adubação nitrogenada), que foram distribuídos em delineamento inteiramente casualizado (devido à homogeneidade da área), com quatro repetições. Foram coletadas amostras de solo na camada de 0 a $20 \mathrm{~cm}$ e enviadas para análise 
em laboratório especializado. Sua classificação é tipo Latossolo Vermelho Amarelo (EMBRAPA, 2006) e apresentou as seguintes características químicas: $\mathrm{pH}\left(\mathrm{H}_{2} \mathrm{O} ; 1: 2,5\right)-5,4 ; \mathrm{Na}$ $\left(\mathrm{mg} / \mathrm{dm}^{3}\right): 20 ; \mathrm{Ca}-\mathrm{KCl}-1 \mathrm{~mol} / \mathrm{L}$ $\left(\mathrm{cmol}_{\mathrm{d}} / \mathrm{dm}^{3}\right): 4,7 ; \mathrm{Mg}-\mathrm{KCl}-1 \mathrm{~mol} / \mathrm{L}$ $\left(\mathrm{cmol}_{\mathrm{C}} / \mathrm{dm}^{3}\right): 2,2 ; \mathrm{Al}-\mathrm{KCl}-1 \mathrm{~mol} / \mathrm{L}$ $\left(\mathrm{cmol}_{\mathrm{d}} / \mathrm{dm}^{3}\right): 0,0 ; \mathrm{H}+\mathrm{Al}-$ Acetato de cálcio $0,5 \mathrm{~mol} / \mathrm{L}\left(\mathrm{cmol}_{\mathrm{C}} / \mathrm{dm}^{3}\right): 4,0 ; \mathrm{SB}$ $\left(\mathrm{cmol}_{\mathcal{C}} / \mathrm{dm}^{3}\right)$ : 7,23; CTC Efetiva: 7,29; CTC $\left(\mathrm{cmol}_{\mathrm{c}} / \mathrm{dm}^{3}\right): 11,23 ; \mathrm{V}(\%): 64,4 ; \mathrm{m}$ (\%): 0,$8 ; \mathrm{P}\left(\mathrm{mg} / \mathrm{dm}^{3}\right): 68 ; \mathrm{K}\left(\mathrm{mg} / \mathrm{dm}^{3}\right)$ : 142; Fe $\left(\mathrm{mg} / \mathrm{dm}^{3}\right): 55,48 ; \mathrm{Cu}\left(\mathrm{mg} / \mathrm{dm}^{3}\right)$ : 1,$91 ; \mathrm{Zn}\left(\mathrm{mg} / \mathrm{dm}^{3}\right): 2,22 ; \mathrm{Mn}\left(\mathrm{mg} / \mathrm{dm}^{3}\right)$ : 37,14; Matéria orgânica total (\%): 1,17.

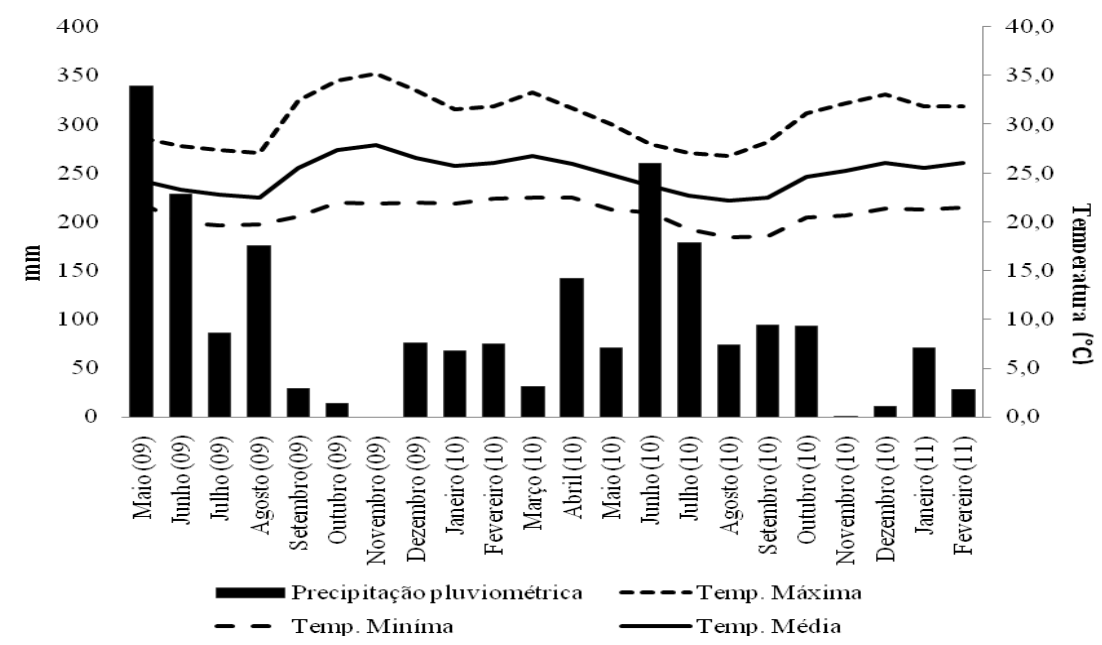

Figura 1.Precipitação pluviométrica média mensal do município de Arapiraca - AL, durante o período experimental (Fonte: INMET)

De acordo com o resultado da análise de solo, foram aplicados $20 \mathrm{~kg} / \mathrm{ha}$ de $\mathrm{P}_{2} \mathrm{O}_{5}$ na forma de superfosfato simples (aplicada de forma localizada na linha de plantio). As adubações nitrogenada (de acordo com os tratamentos), na forma de ureia, e potássica $(60 \mathrm{~kg} / \mathrm{ha}$ de $\mathrm{K}_{2} \mathrm{O}$ ), sob a forma de cloreto de potássio, foram realizadas em três aplicações (1/3 da dose), a lanço, a cada 30 dias. No segundo ano, repetiu-se a adubação de acordo com a metodologia do primeiro.

O preparo convencional do solo teve início em junho de 2009. As parcelas experimentais possuíam cinco linhas com um metro de comprimento $\left(5 \mathrm{~m}^{2}\right)$, e cada uma era composta por cinco plantas. Os cladódios utilizados no ensaio foram provenientes de palmais, formados com a variedade miúda (Nopalea cochenillifera (L.) SD., Cact. Hort. Dyck. 1849), com idade aproximada de três anos. Os cladódios foram distribuídos nas parcelas experimentais e, para isso, utilizou-se densidade de plantio de 40.000 plantas por hectare, equivalente ao espaçamento de plantio de 1 x $0,25 \mathrm{~m}$. Durante a condução do experimento, quando necessário, foi realizado controle de plantas invasoras manualmente.

Para as avaliações das características morfogênicas, foram selecionadas três plantas por parcela da linha central e, à medida que os cladódios surgiram, os mesmos foram quantificados e marcados, semanalmente, com fios de cores diferentes, segundo a ordem de aparecimento na hierarquia dos 
cladódios. Assim, calculou-se a taxa de aparecimento de cladódio (TApC, cladódio/dia) e o filocrono (dia/cladódio) dos cladódios. Semanalmente, com a utilização de régua e paquímetro, foi mensurado o comprimento, largura e espessura dos cladódios, o que permitiu estimar as taxas de alongamento de cladódio (TAlC em $\mathrm{cm} / \mathrm{dia}$ ), de alargamento de cladódio (TAC em cm/dia), de espessamento de cladódio (TEC em $\mathrm{cm} / \mathrm{dia}$ ), de expansão de área (TEA em $\mathrm{cm}^{2} /$ dia) e de expansão de volume (TEV $\mathrm{cm}^{3} /$ dia). As taxas de alongamento, alargamento e espessamento foram calculadas ao subtrair a última medição pela primeira e dividir pelo número de dias.

O número de cladódios foi obtido por intermédio da contagem na planta. Em fevereiro de 2011, três plantas por parcela foram colhidas e pesadas. Manteve-se intacto apenas o cladódio proveniente do plantio. A massa fresca de cada planta foi obtida pela soma das massas de seus cladódios. A massa média dos cladódios foi obtida ao se dividir a massa fresca pelo número de cladódios da planta. Com base nas massas das plantas de cada parcela, foi calculada a massa média das plantas por parcela. A produção de massa fresca por hectare foi calculada ao se multiplicar a massa média das plantas de cada parcela pelo número de plantas por hectare (40.000 plantas/ha).

Após as pesagens, foram mensurados nos cladódios, o comprimento, largura e espessura (no centro do cladódio). Com a utilização dos dados de comprimento e largura dos cladódios, foi possível estimar a área (A) de cada cladódio, ao se considerar uma aproximação em relação à área da elipse:

$$
A=\pi\left(\frac{C+L}{4}\right)^{2}
$$

Em que: $\mathrm{C}=$ Comprimento; $\mathrm{L}=$ Largura

$\mathrm{O}$ volume foi estimado ao se multiplicar a área de cada cladódio por sua respectiva espessura. Os dados foram submetidos à análise de variância e de regressão. A significância da regressão foi testada pelo teste F, e o coeficiente de regressão foi testado pelo teste $\mathrm{T}$, cujo nível de significância adotado foi $10 \%$. Foi utilizado o procedimento GLM do SAS 9.2 (SAS INSTITUTE, 2008).

Foi realizada análise de correlação entre a massa fresca e comprimento, largura, espessuras (na base, centro e ápice dos cladódios, expressas em milímetros), área e volumes dos cladódios, estimados a partir dos três valores de espessura. Foram utilizadas medidas de 4.502 cladódios de 144 plantas. O coeficiente de correlação de Pearson (r) foi calculado como demonstrado a seguir:

$r=\frac{\mathbf{\Sigma} x y-\frac{(\mathbf{\Sigma} x)(\mathbf{\Sigma} y)}{n}}{\sqrt{\left[\mathbf{\Sigma} x^{2}-\frac{(\mathbf{\Sigma} x)^{2}}{n}\right] \cdot\left[\mathbf{\Sigma} y^{2}-\frac{(\mathbf{\Sigma} y)^{2}}{n}\right]}}$

Em que: $y$ corresponde ao peso dos cladódios, e $x$ ao comprimento, largura, espessura, área e volume dos cladódios. A significância da correlação foi avaliada pelo teste T. A análise de correlação foi realizada pelo procedimento Corr do SAS.

\section{RESULTADOS E DISCUSSÃO}

Não houve efeito $(\mathrm{P}>0,10)$ da adubação nitrogenada para as características morfogênicas (Tabela 1). Efeitos significativos nessas características poderiam ser esperados, pelo fato de o nitrogênio agir como estimulador de divisão e alongamento celular, o que 
promoveria efeitos diretos no comprimento dos cladódios.

Em estudos ecofisiológicos de Poaceas forrageiras, é comum o uso de taxas de crescimento para avaliação de fluxo de tecidos, as quais têm sido primordiais para o estabelecimento de estratégias de manejo. Entretanto, para palma forrageira, a maioria dos estudos versa sobre a produção de massa seca. Pesquisas dessa natureza são destrutivas, cujos dados somente podem ser obtidos a partir do segundo ano de plantio. Assim, o conhecimento das taxas de crescimento pode ser uma ferramenta usual no estudo do desenvolvimento de tais plantas.

Tabela 1. Equações de regressão e médias de características morfogênicas de cladódios de palma miúda sob doses de nitrogênio

\begin{tabular}{|c|c|c|c|c|c|c|c|}
\hline \multirow{2}{*}{$\begin{array}{l}\text { Características } \\
\text { morfogênicas }\end{array}$} & \multicolumn{4}{|c|}{ Doses de nitrogênio } & \multirow{2}{*}{ Equação } & \multirow{2}{*}{$\begin{array}{l}\text { Regr. } \\
\text { Sig F }\end{array}$} & \multirow{2}{*}{$\begin{array}{c}\beta 1 \\
\text { Sig T }\end{array}$} \\
\hline & 0 & 100 & 200 & 300 & & & \\
\hline TAlC (cm/dia) & 0,31 & 0,34 & 0,34 & 0,36 & $\hat{\mathrm{Y}}=0,3394$ & 0,6441 & 0,1581 \\
\hline TAC (cm/dia) & 0,13 & 0,14 & 0,14 & 0,15 & $\hat{\mathrm{Y}}=0,1425$ & 0,9148 & 0,4440 \\
\hline TEC $(\mathrm{cm} / \mathrm{dia})$ & 0,019 & 0,022 & 0,022 & 0,023 & $\hat{\mathrm{Y}}=0,0215$ & 0,3298 & 0,2060 \\
\hline TEA ( $\left.\mathrm{cm}^{2} / \mathrm{dia}\right)$ & 0,914 & 0,894 & 1,032 & 1,028 & $\hat{\mathrm{Y}}=0,9671$ & 0,5571 & 0,1864 \\
\hline TEV (cm³/dia) & 144,3 & 134,3 & 136,6 & 136,7 & $\hat{\mathrm{Y}}=0,9072$ & 0,3900 & 0,2962 \\
\hline TApC (Cl./dia) & 0,0962 & 0,1033 & 0,1096 & 0,1249 & $\hat{\mathrm{Y}}=0,1085$ & 0,1427 & 0,1280 \\
\hline Filocrono & 12,65 & 11,33 & 10,51 & 10,24 & $\hat{\mathrm{Y}}=11,180$ & 0,4909 & 0,0781 \\
\hline
\end{tabular}

Sig F = significância da regressão pelo teste $\mathrm{F} ; \beta 1=$ significância do coeficiente de regressão testado pelo teste $\mathrm{T} ; \mathrm{TAlC}=$ taxa de alongamento de cladódio; $\mathrm{TAC}=$ taxa alargamento de cladódio $; \mathrm{TEC}=$ taxa de espessamento de cladódio; TEA = taxa de expansão de área; $\mathrm{TEV}$ = taxa de expansão de volume; $\mathrm{TApC}=$ taxa de aparecimento de cladódios.

$\mathrm{O}$ nitrogênio promoveu efeito linear e positivo $(\mathrm{P}<0,10)$ no número de cladódios (Tabela 2), com valores que variavam de 27,75 a 36,08 cladódios, para ausência de adubação e para a dose de $300 \mathrm{~kg} / \mathrm{ha}$ de $\mathrm{N}$, respectivamente. Isso se explica pelo fato de o nitrogênio ser o nutriente que estimula a divisão celular e promove o aparecimento de novos cladódios. Dubeux Júnior et al. (2010) não verificaram efeito significativo da adubação fosfatada e potássica no número de cladódios de palma forrageira. Teles et al. (2002), também não observaram efeito significativo de fósforo e potássio para número de cladódios primários, porém, para número total de cladódios por planta e número de cladódios secundários, observaram diferença significativa entre tratamentos.
Lemaire \& Chapman (1996) mostraram que a taxa de aparecimento de folhas tem papel central na morfogênese, devido à influência direta sobre cada um dos três componentes da estrutura do pasto. Existe uma correlação entre a TApF com a densidade populacional de perfilhos (número de cladódios no caso da palma forrageira), pois cada lâmina foliar surgida representa potencialmente o aparecimento de um novo perfilho (ou novos cladódios), devido à geração de novas gemas axilares. Assim, embora não tenha apresentado diferenças significativas, em valores absolutos, a TApC aumentou de acordo com a disponibilidade de nitrogênio, o que pode ter acarretado a elevação linear no número de cladódios. 
Não se observou efeito significativo $(\mathrm{P}<0,10)$ para a característica comprimento dos cladódios. Observou-se efeito linear negativo $(\mathrm{P}<0,05)$ da adubação nitrogenada sobre a largura, espessura, volume e peso médio dos cladódios (Tabela 2). O decréscimo, tanto para os valores médios da característica espessura, quanto para volume dos cladódios, pode ser um reflexo da elevação da quantidade de cladódios com o aumento da disponibilidade de nitrogênio, visto que a planta necessita distribuir os nutrientes para uma maior quantidade de cladódios, o que influencia na espessura das mesmas. Atribui-se o menor peso dos cladódios, com o aumento da adubação nitrogenada, à maior deposição de massa seca por cladódio nessas plantas, uma vez que a competição por nutrientes é menor em termos de número de cladódios. Portanto, as plantas tendem a aumentar o número de cladódios, quando se elevam os níveis de nitrogênio, consequentemente, a variação na distribuição dos nutrientes influencia as características de desenvolvimento dos mesmos.

Tabela 2. Equações de regressão e médias de características morfológicas de plantas de palma miúda sob doses de nitrogênio

\begin{tabular}{|c|c|c|c|c|c|c|c|c|}
\hline \multirow{2}{*}{$\begin{array}{l}\text { Características } \\
\text { morfológicas }\end{array}$} & \multicolumn{4}{|c|}{ Doses de nitrogênio } & \multirow{2}{*}{ Equação } & \multirow{2}{*}{$\mathrm{r}^{2}$} & \multirow{2}{*}{$\begin{array}{l}\text { Regr. } \\
\text { Sig F }\end{array}$} & \multirow{2}{*}{$\begin{array}{r}\beta 1 \\
\text { Sig T }\end{array}$} \\
\hline & 0 & 100 & 200 & 300 & & & & \\
\hline $\mathrm{N}^{\circ}$ cladódios & 27,75 & 30,19 & 31,00 & 36,08 & $\hat{\mathrm{Y}}=27,38+0,026 \mathrm{~N}$ & 0,258 & 0,0912 & 0,0764 \\
\hline Compr. (cm) & 18,37 & 17,72 & 17,98 & 17,98 & $\hat{\mathrm{Y}}=18,01$ & - & 0,3247 & 0,3710 \\
\hline Larg. $(\mathrm{cm})$ & 8,41 & 8,02 & 8,06 & 8,05 & $\hat{\mathrm{Y}}=8,29-0,001 \mathrm{~N}$ & 0,439 & 0,0248 & 0,0188 \\
\hline Espes. $(\mathrm{cm})$ & 1,70 & 1,62 & 1,65 & 1,59 & $\hat{\mathrm{Y}}=1,68-0,0003 \mathrm{~N}$ & 0,344 & 0,0271 & 0,0448 \\
\hline Área $\left(\mathrm{cm}^{2}\right)$ & 144,3 & 134,3 & 136,6 & 136,7 & $\hat{Y}=137,99$ & 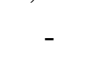 & 0,1568 & 0,1272 \\
\hline Vol. $\left(\mathrm{cm}^{3}\right)$ & 247,9 & 223,4 & 229,0 & 220,2 & $\hat{\mathrm{Y}}=241,74-0,07 \mathrm{~N}$ & 0,450 & 0,0356 & 0,0169 \\
\hline $\operatorname{PMC}(\mathrm{g})$ & 158,2 & 140,5 & 144,5 & 137,0 & $\hat{\mathrm{Y}}=154-0,059 \mathrm{~N}$ & 0,453 & 0,0311 & 0,0164 \\
\hline PMP (g) & 4384 & 4245 & 4482 & 4927 & $\hat{Y}=4509,98$ & - & 0,5600 & 0,3443 \\
\hline PM (Ton/ha) & 175,4 & 169,8 & 179,3 & 197,1 & $\hat{\mathrm{Y}}=180,39$ & - & 0,5600 & 0,3443 \\
\hline
\end{tabular}

Sig F = significância da regressão pelo teste $\mathrm{F} ; \beta 1=$ Significância do coeficiente de regressão testado pelo teste $\mathrm{T} ; \mathrm{PMC}=$ peso médio dos cladódios; $\mathrm{PMP}=$ peso médio das plantas; $\mathrm{PM}=$ produtividade média.

Não houve efeito $(\mathrm{P}>0,10)$ da adubação nitrogenada para produção de massa fresca em toneladas por hectare. A produção de massa fresca por hectare apresentou valores de 175,36 toneladas para a ausência de adubação a 197 toneladas, para o tratamento com $300 \mathrm{~kg}$ de N. Não se observou efeito da adubação $(\mathrm{P}>0,10)$ sobre os valores médios das características área e massa das plantas (Tabela 2). Ao se tratar das características referentes à massa fresca dos cladódios (produção em toneladas por hectare e massa média das plantas), as mesmas têm importância desconsiderada, uma vez que possuem pouca relevância em estudos com outras plantas forrageiras. Por ser de fácil aferição e visualização, a produção de massa fresca, por vezes, é utilizada para o dimensionamento e controle do fluxo de animais (principalmente nas épocas secas). Outro ponto que deve ser considerado, no que concerne à importância da produção de massa fresca, centra-se no fato de que a quantidade de água advinda dessa biomassa é elevada. 
A ausência de diferenças estatísticas para grande parte das características avaliadas pode advir de características inerentes à dinâmica do desenvolvimento do sistema radicular da palma forrageira, além da fonte de nitrogênio utilizada. A distribuição irregular da precipitação pluviométrica que, por vezes, concentrase em três ou quatro meses, pode gerar curtos períodos de crescimento pleno das raízes, cuja grande parte destas vêm a sucumbir com a entrada da estação seca. Dessa forma, este pode ser um mecanismo de economia de fotoassimilados e água pela planta.

Visto a ureia ser uma fonte passível de perdas por volatilização, além da lixiviação, o sistema radicular da palma denota não ser capaz de absorver, de maneira eficiente, grande parte do nitrogênio, aplicado via adubação, antes que o mesmo seja perdido para o meio ambiente. Tal afirmativa se ratifica ao se considerar o estudo de Gonzalez (1989). O autor observou efeito positivo da aplicação do nitrogênio e fósforo na produção de massa seca da Opuntia lindheimeri Engelm. em experimentos de longa duração, porém não observou efeitos da adubação nos primeiros dois anos após plantio. Zuñiga-Tarango et al. (2009) observaram variações na produção de massa seca e densidade de raízes, respectivamente, ao longo do período de amostragens.

Foi observada correlação $(\mathrm{P}<0,0001)$ das medidas de comprimento, largura, espessura, área e volume com a massa fresca dos cladódios (Figuras 2 e 3 ). Isso comprova a existência de associação linear entre a massa fresca dos cladódios e as demais variáveis. Embora os graus de associação linear entre a massa fresca com comprimento, largura, espessura e área possam ser considerados relativamente elevados, os maiores coeficientes de correlação foram obtidos com a utilização das medidas de volume dos cladódios. Para o cálculo da estimativa de volume dos cladódios, foram utilizadas as medições de comprimento, largura e espessura dos cladódios (três dimensões), o que garantiu que o volume dos cladódios apresentasse os maiores coeficientes de correlação dentre as demais características.

Em relação à espessura, a maior correlação foi obtida quando as medidas foram tomadas na base dos cladódios. Entretanto, o volume se correlacionou melhor com o peso, quando foi calculado com a utilização das medidas de espessura, tomadas no centro dos cladódios. As medidas tomadas nas extremidades do cladódio (ápice e base), a depender do estádio de desenvolvimento do cladódio, não representam de maneira fidedigna a espessura média do cladódio. Com o aumento do peso das ordens subsequentes, os cladódios de ordens inferiores passam a aumentar a espessura na base (incremento dos tecidos de sustentação) para sustentar de maneira eficiente o peso da planta. Mesmo em cladódios completamente expandidos, a espessura do ápice do cladódio ainda assim permanece como a região menos espessa, a subestimar qualquer estimativa que a utilize como base de cálculo.

Devido aos valores do coeficiente de correlação entre o volume e massa fresca, é possível afirmar que o volume pode ser usado como variável preditora para o peso dos cladódios (Figura 2). Isso é importante na realização de estudos não destrutivos que visem o acompanhamento do desenvolvimento das plantas de palma forrageira. Nesse cenário, pode ser possível também o desenvolvimento de equações para obtenção de estimativas de produção de massa de palma forrageira, em condições de campo, quando na ausência de balanças. 
Rev. Bras. Saúde Prod. Anim., Salvador, v.13, n.4, p.1156-1165 out./dez., 2012 http://www.rbspa.ufba.br ISSN 15199940


Figura 2. Coeficientes de correlação (r) e significância da correlação (P) entre o comprimento, largura, espessura e peso dos cladódios
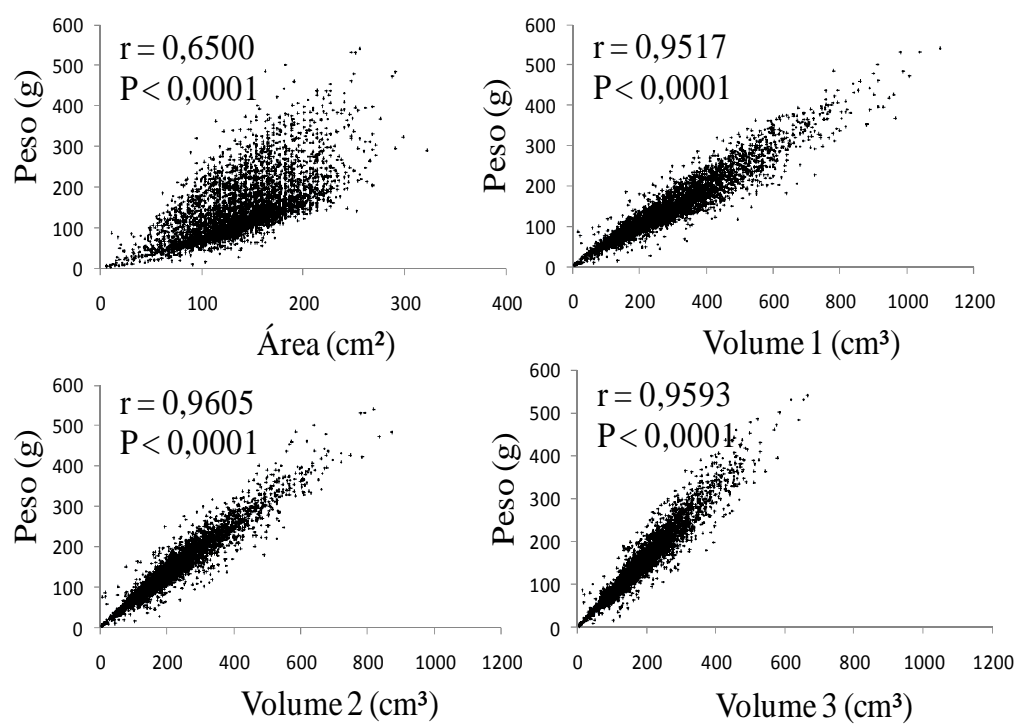

Figura 3. Coeficientes de correlação (r) e significância da correlação $(\mathrm{P})$ entre a área, volume e peso dos cladódios. Volume $1=$ calculado com a espessura da base dos cladódios, Volume 2= calculado com a espessura do centro dos cladódios, Volume $3=$ calculado com a espessura do ápice dos cladódios 
O uso da adubação nitrogenada não interfere nas características morfogênicas e na produção de biomassa da palma forrageira. $\mathrm{O}$ volume da palma pode ser usado como variável preditora para o peso fresco dos cladódios.

\section{REFERÊNCIAS}

CAVALCANTI, C.V.A.; FERREIRA, M.A.; CARVALHO, M.C.; VÉRAS, A.S.C.; SILVA, F.M.; LIMA, L.E.

Palma forrageira enriquecida com ureia em substituição ao feno de capim tifton 85 em rações para vacas da raça Holandesa em lactação. Revista Brasileira de Zootecnia, v.37, n.4, p.689-693, 2008.

DUBEUX JR., J.C.B.; ARAÚJO FILHO, J.T.; SANTOS, M.V.F.; LIRA, M.A.; SANTOS, D.C.; PESSOA, R.A.S. Adubação mineral no crescimento e composição mineral da palma forrageira - Clone IPA-20.

Revista Brasileira de Ciências Agrárias, v.5, n.1, p.129-135, 2010.

EMPRESA BRASILEIRA DE PESQUISA AGROPECUÁRIA EMBRAPA. Centro Nacional de Pesquisa de Solos. Sistema Brasileiro de classificação de solos. 2.ed. Rio de Janeiro: Embrapa Solos, 2006.

GONZALEZ, C.L. Potential of fertilization to improve nutritive value of prickly pear cactus (Opuntia lindheimeri Engelm.). Journal of Arid Environments, v.16, p.87-94, 1989.

LEMAIRE, G.; CHAPMAN, D. Tissue flows in grazed plant communities. In: HODGSON, J.; ILLIUS, A. W. (Eds.). The ecology and management of grazing systems. London: $\mathrm{CAB}$ International, 1996. p.3-36.
MAGALHÃES, M.C.S.; VÉRAS, A.S.C.; FERREIRA, M.A.; CARVALHO, F.F.R, CECON, P.R.; MELO, J.N.; MELO, W.S.; PEREIRA, J.T. Inclusão de cama de frango em dietas à base de Palma Forrageira (Opuntia ficusindica Mill) para vacas mestiças em lactação. 1. Consumo e produção. Revista Brasileira de Zootecnia, v.33, n.6, p.1897-1908, 2004. Supl. 1.

MELO, A.A.S.; FERREIRA, M.A.; VERAS, A.S.C.; LIRA, M. A.; LIMA, L. E.; VILELA, M. S.; MELO, E. O. S.; ARAÚJO, P. R. B. Substituição parcial do farelo de soja por ureia e palma forrageira em dietas para vacas em lactação. Digestibilidade. Acta Scientiarum. Animal Sciences, v. 25 n.2, p.339-345, 2003.

SANTOS, D.C.; FARIAS I.; LIRA, M.A.; TAVARES FILHO, J.J.; SANTOS, M.V.F.; ARRUDA, G.P. A palma forrageira (Opuntia ficusindica Mill e Nopalea cochenillifera Salm-Dyck) em Pernambuco: cultivo e utilização. Recife: IPA, 1997. 23p. (Documentos IPA, 25).

SAS INSTITUTE. SAS user's guide: statiscs. Version 9.2. Cary, 2008. $1028 \mathrm{p}$.

SILVA, N.G.M.; LIRA, M.A.; SANTOS, M.V.F.; DUBEUX JÚNIOR, J.C.B.; MELLO, A.C.L.; SILVA, M.C. Relação entre características morfológicas e produtivas de clones de palma-forrageira. Revista Brasileira de Zootecnia, v.39, n.11, p.2389-2397, 2010.

TELES, M.M.; SANTOS, M.V.F.; DUBEUX JÚNIOR, J.C.B.; BEZERRA NETO, E.; FERREIRA, R. L.C.; LUCENA, J. E.C.; LIRA, M.A. Efeitos da adubação e de nematicida no 
Rev. Bras. Saúde Prod. Anim., Salvador, v.13, n.4, p.1156-1165 out./dez., 2012 http://www.rbspa.ufba.br ISSN 15199940

crescimento e na produção da palma forrageira (Opuntia fícus-indica Mill.) cv. Gigante. Revista Brasileira de Zootecnia, v.31, n.1, p.52-60, 2002.

WANDERLEY, W.L.; FERREIRA, M.A.; ANDRADE, D.K.B. VÉRAS, A.S.C.; FARIAS, I.; LIMA, L. E.; DIAS, A.M.A. Palma forrageira (Opuntia ficus indica Mill) em substituição à silagem de sorgo (Sorghum bicolor (L.) Moench) na alimentação de vacas leiteiras. Revista Brasileira de Zootecnia, v.31, n.1, p.273-281, 2002.
ZÚÑIGA-TARANGO, R.; ORONACASTILLO, I.; VÁZQUEZ-

VÁZQUEZ, C.; MURILLO-

AMADOR, B.; SALAZAR-SOSA, E.; LÓPEZ-MARTÍNEZ, J. D.; GARCÍAHERNÁNDEZ, J.L.; RUEDA-

PUENTE, E. Desarrollo radical, rendimiento y concentración mineral en nopal Opuntia ficus-indica (L.) Mill. en diferentes tratamientos de fertilización.

Journal of the Professional Association for Cactus Development, v.11, p.53-68, 2009.

Data de recebimento: 03/02/2012

Data de aprovação: 22/11/2012 